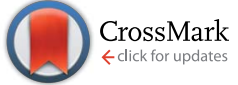

Cite this: RSC Adv., 2014, 4, 42044

\title{
Diamond functionalization with light-harvesting molecular wires: improved surface coverage by optimized Suzuki cross-coupling conditions $\uparrow$
}

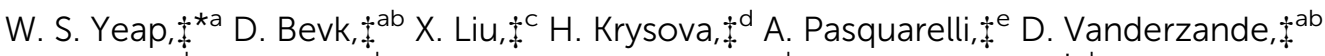

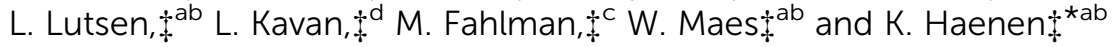 \\ Donor-acceptor type light-harvesting molecular wires are covalently attached to a boron-doped diamond \\ surface via a combination of diazonium electrografting and Suzuki cross-coupling. For the Suzuki reaction, \\ various catalytic systems are compared with respect to their imposed surface coverage. Combining 2- \\ dicyclohexylphosphino-2',6'-dimethoxybiphenyl (SPhos) and $\mathrm{Pd}(0)$, the diamond coverage improves \\ considerably (by $98 \%$ ) as compared to the standard tetrakis(triphenylphosphine)palladium(0) $\left(\mathrm{Pd}\left(\mathrm{PPh}_{3}\right)_{4}\right)$ \\ catalyst. As the energy levels between the molecular chromophores and the diamond film align well, the \\ sophisticated functionalized diamond surfaces present a first step towards the development of fully \\ carbon-based devices for light to electricity conversion.
}

Received 20th May 2014

Accepted 28th August 2014

DOI: $10.1039 / \mathrm{c} 4 \mathrm{ra0} 4740 \mathrm{k}$

www.rsc.org/advances

modification schemes, allowing the attachment of various

\section{Introduction}

In recent years, boron-doped diamond (BDD) has become increasingly important within science and technology. ${ }^{1}$ By adding boron, diamond conductivity can be tuned, with values ranging from $1 \times 10^{-9}$ to $100 \Omega^{-1} \mathrm{~cm}^{-1}$, the latter resulting in metallic behavior. ${ }^{2}$ Boron-doped nanocrystalline diamond (B:NCD) prepared with a thickness of $\sim 150 \mathrm{~nm}$ is highly transparent (with a transmission of $70-80 \%$ ). ${ }^{3}$ Despite its extraordinary physical properties and numerous applications (chemical and biosensors, electrosynthesis etc.), ${ }^{4}$ earlier works focused mostly on tailoring the diamond's surface properties. Photochemical modification, ${ }^{5}$ plasma treatment, ${ }^{6}$ and diazonium coupling ${ }^{7}$ afford a diversity of diamond surface

${ }^{a}$ Hasselt University, Institute for Materials Research (IMO), B-3590 Diepenbeek, Belgium. E-mail: wengsiang.yeap@uhasselt.be; Fax: +32 1126 8899; Tel: +32 1126 8826

${ }^{b} I M E C$ vzw, IMOMEC, B-3590 Diepenbeek, Belgium.E-mail: ken.haenen@uhasselt.be ${ }^{c}$ Linköping University, Department of Physics, Chemistry and Biology, S-58183 Linköping, Sweden

${ }^{d}$ Academy of Sciences of The Czech Republic, J. Heyrovsky Institute of Physical Chemistry, v.v.i., Dolejškova 3, CZ-182 23 Prague 8, Czech Republic

${ }^{e}$ Ulm University, Institute of Electron Devices and Circuits, 89069 Ulm, Germany

$\dagger$ Electronic supplementary information (ESI) available: ${ }^{1} \mathrm{H}$ and ${ }^{13} \mathrm{C}$ NMR and UV-Vis spectra of Br-CPDT-Fur. See DOI: 10.1039/c4ra04740k

\$ W.S.Y., L.L., W.M., and K.H. conceived the concept and designed the experiments. W.S.Y. performed the diamond growth and surface functionalization in K.H., W.M., and D.V.'s labs. Surface studies were carried out in M.F.'s lab. D.B. performed the synthesis of the Br-CPDT-Fur and Br-BT-Rho dyes. L.X. performed the photoelectron spectroscopy measurements. A.P. and H.K. performed the photoelectrochemical measurements. W.S.Y., D.B., L.X., W.M., L.K., and K.H. discussed the data and wrote the manuscript. All authors provided comments on the manuscript. molecular structures. The next challenge, however, is to develop a versatile chemistry that can impart useful sensory, optoelectronic and/or photophysical properties to the B:NCD material.

Next to several click chemistry protocols, ${ }^{8}$ the SuzukiMiyaura reaction represents one of the most versatile and powerful carbon-carbon (most often aryl-aryl) bond forming procedures in modern synthetic chemistry. ${ }^{9}$ This Pd-catalyzed cross-coupling reaction has been applied for the preparation of a huge variety of conjugated aromatic compounds, for example to be used for organic light-emitting diodes (OLEDs), ${ }^{10}$ polymer LEDs, ${ }^{11}$ organic photovoltaics,${ }^{12}$ and nonlinear optical materials. ${ }^{13}$ The Suzuki reaction can also be used for (uninterrupted) molecular conjugation of solid surfaces to a large class of organic molecules. ${ }^{14}$ This is particularly useful if one wishes to create donor-acceptor type molecular wires on semiconducting substrates for photocurrent/photovoltage generation. ${ }^{15}$ However, to the best of our knowledge, there are only three reports so far which address Suzuki cross-coupling reactions on diamond surfaces. ${ }^{16-18}$ Zhong et al. reported a facile method for the Suzuki coupling of oligothiophene-fullerene and 2(dicyanovinyl)-5-iodobithiophene molecular wires onto diamond. They showed that this method opens up possibilities for the application of diamond in molecular electronics and photovoltaics. Nonetheless, the reported surface coverage of 2(dicyanovinyl)-5-iodobithiophene was as low as 0.41 'monolayer' (ML) (relative to a high quality reference monolayer of dodecanethiol on $\mathrm{Au}$, as determined by X-ray photoelectron spectroscopy, XPS). ${ }^{17}$

In this manuscript, we report on the successful decoration of B:NCD with two molecular wire systems, $(Z)-2-\left\{5-\left[\left(5^{\prime}\right.\right.\right.$-bromo[2,2'-bithiophen]-5-yl)methylene]-4-oxo-2-thioxothiazolidin-3-yl $\}$ 
acetic acid (Br-BT-Rho) and (E)-2-\{4-[2-(6-bromo-4,4-diethyl-4Hcyclopenta[1,2-b:5,4- $\left.b^{\prime}\right]$ dithiophen-2-yl)vinyl]-3-cyano-5,5-dimethylfuran-2(5H)-ylidene\}malononitrile (Br-CPDT-Fur) (Scheme 1), via optimized Suzuki cross-coupling reactions. Both molecular wires possess a bromoaryl moiety to enable reaction with an arylboronic ester functionalized B:NCD surface. The most effective catalytic system was pursued to increase the coupling efficiency and hence the surface coverage. Surface functionalization as well as coverage were determined by XPS. The CPDTFur molecular wire has suitable properties to be used effectively in future molecular photovoltaic systems, i.e. high absorbance, wide absorption and good charge transfer abilities through the $\pi$-system. ${ }^{19}$ Furthermore, the highest occupied molecular orbital (HOMO) of the dye seems to match well with the valence band of the B:NCD film, as evaluated by ultraviolet photoelectron spectroscopy (UPS), allowing hole injection from the dye to diamond.

\section{Results and discussion}

As shown in Scheme 1, the anchoring of the molecular wires onto the diamond surface begins with the functionalization of hydrogen-terminated B:NCD (see Experimental) with arylboronic ester moieties through diazonium electrografting. ${ }^{16}$ Two light-harvesting molecular wires with a donor-acceptor structure (to increase light-harvesting and enhance charge separation), Br-BT-Rho and Br-CPDT-Fur (Scheme 1), were presynthesized in solution before undergoing Suzuki coupling to the B:NCD surfaces. Both molecular wires contain an electronrich (bridged) bithiophene 'donor' part and an electrondeficient subunit and they carry a reactive arylbromide group on the donor part. As the B:NCD film is finally intended to be used as the hole conductor in photovoltaic devices, the donor part of the chromophores has to be attached to the diamond surface. The Br-BT-Rho chromophore was synthesized by reacting commercially available 5-bromo-5'-formyl-2,2'-bithiophene with rhodanine-3-acetic acid in a standard condensation reaction. On the other hand, the Br-CPDT-Fur molecule was synthesized according to the procedure outlined in Scheme 2 .

$4 H$-Cyclopenta[1,2-b:5,4- $\left.b^{\prime}\right]$ dithiophenes (CPDTs) have been proven to be attractive electron donating building blocks for applications in organic electronics due to the planarity of the bridged bithiophene system and the excellent charge transfer capabilities through the molecule. ${ }^{19}$ For the purpose of B:NCD functionalization, a novel CPDT chromophore has been developed, employing a furan group as the acceptor part attached to the CPDT core via a vinyl bridge. The synthesis of the CPDT core was done according to two different previously published procedures. ${ }^{19 a, 20}$ CPDT formylation was performed using a standard Vilsmeier-Haack procedure in 1,2-dichloroethane at $0{ }^{\circ} \mathrm{C}$. This reaction yielded exclusively monoformylated CPDT derivative 2 , which was used in the next step without prior purification. Treatment of CPDT-CHO 2 with $N$-bromosuccinimide (NBS) at room temperature furnished Br-CPDT-CHO derivative 3 in a smooth manner. To attach the furan acceptor, a Knoevenagel condensation reaction was performed in the presence of a catalytic amount of piperidine. The Br-CPDT-Fur dye precipitated from the hot reaction mixture and was recrystallized from the corresponding solvent and used as such. UV-Vis analysis of the dye showed a high extinction coefficient $\left(\varepsilon=73100 \mathrm{~L} \mathrm{~mol}^{-1}\right.$ $\mathrm{cm}^{-1}$ at $\lambda=582 \mathrm{~nm}$ ), thus proving suitability of the molecule for the envisaged application. The frontier orbital energy levels, as

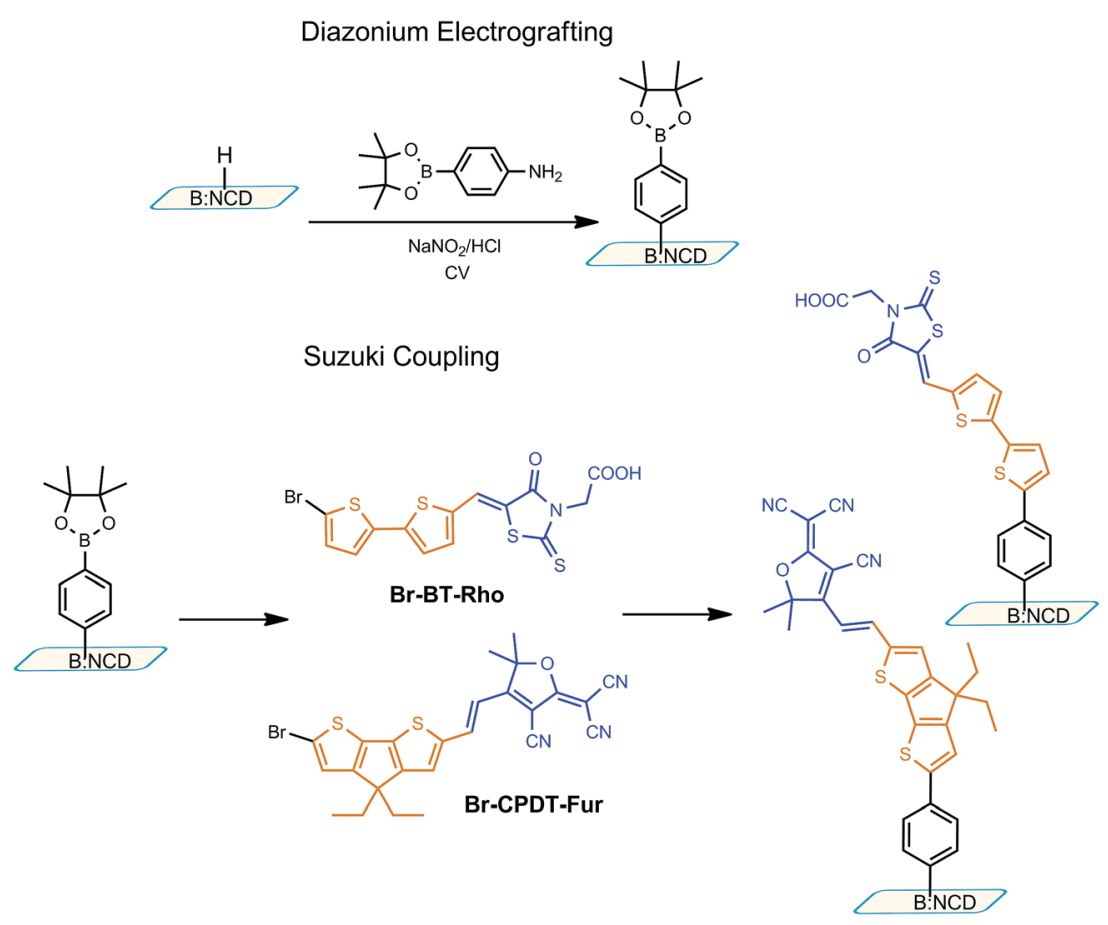

Scheme 1 Diazonium electrografting and Suzuki cross-coupling towards effective B:NCD functionalization. 

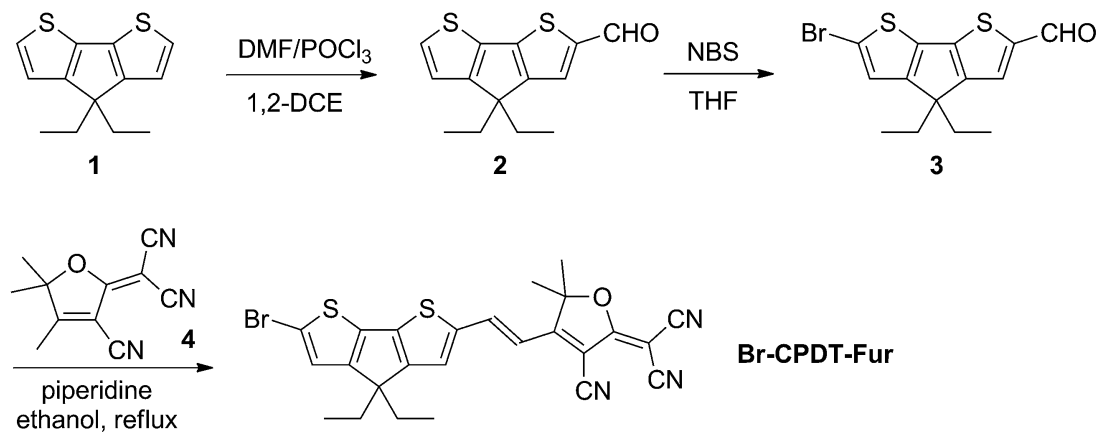

Scheme 2 Synthetic protocol towards the Br-CPDT-Fur molecular wire.

determined from the oxidation and reduction onsets derived from cyclic voltammetry (CV), are $E_{\mathrm{HOMO}}=-5.70 \mathrm{eV}$ and $E_{\mathrm{LUMO}}$ $=-4.03 \mathrm{eV}$.

Successful electrografting of the arylboronic ester groups on the B:NCD surface by the diazonium approach was confirmed by CV (Fig. 1). The first CV cycle shows two reduction peaks. The broader peak at $-0.6 \mathrm{~V}(v s$. $\mathrm{Ag} / \mathrm{AgCl})$ can be assigned to the formation of arylboronic ester radicals. During the second cycle, this reduction wave disappears and the cyclic voltammogram only exhibits a very small reduction current, which suggests passivation of the diamond surface by the grafted layer, hence blocking the access of the diazonium cations to the surface. A smaller reduction peak appearing at $-0.1 \mathrm{~V}(v s$. $\mathrm{Ag} / \mathrm{AgCl})$ was previously noticed as well for electrografting of 4-nitrophenyland 4-carboxyphenyl-diazonium cations, but its origin is not yet clearly understood. ${ }^{7}$

XPS spectra of the hydrogenated and arylboronic ester functionalized B:NCD films are shown in Fig. 2. As can be seen clearly from the high-resolution XPS spectra, the B 1s peak of the dopant boron atoms in B:NCD is found at $\sim 186 \mathrm{eV}$. After electrografting of the arylboronic ester groups on the B:NCD surface, an additional intense signal appears at $\sim 191 \mathrm{eV}$. This peak is assigned to the B 1s core level in boron atoms from the grafted arylboronic ester layer. ${ }^{16}$ High-resolution XPS clearly shows the presence of two chemically distinct boron species.

The arylboronic ester surface provides an excellent solid phase platform for further $\mathrm{C}-\mathrm{C}$ extension via Suzuki crosscoupling. As such, an 'all-carbon' molecular photovoltaic system could be realized. However, a diamond surface with high chromophore loading is required for this purpose and this high coverage is not trivially obtained. To tackle this, a careful search for the optimum Suzuki conditions on arylboronic ester functionalized B:NCD was conducted. Tables 1 and 2 gather some of the different catalytic systems (changing the Pd catalyst, ligand, base and/or solvent) investigated for the two different chromophores (or their precursors). It should be mentioned at this point that the 'opposite' strategy, coupling 5-(5-formyl-2thienyl)-2-thiopheneboronic acid ((HO) $\left.{ }_{2} \mathrm{~B}-\mathrm{BT}-\mathrm{CHO}\right)$ to a bromophenyl decorated B:NCD surface (obtained via spontaneous grafting of 4-bromobenzenediazonium tetrafluoroborate), was employed as well, but the obtained results were inferior to the procedure outlined here.

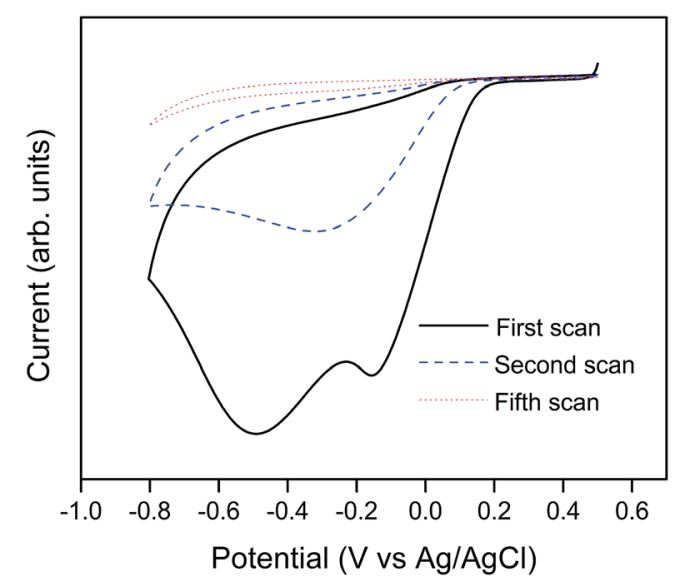

Fig. 1 In situ electrochemical generation of boronic ester derivatized phenyldiazonium cations, showing five CV reduction cycles (first cycle, black solid line; second cycle, blue dashed line; fifth cycle, red dotted line) with applied voltage between +0.5 and $-0.8 \mathrm{~V}$ (scan rate $100 \mathrm{mV} \mathrm{s}^{-1}$ ).
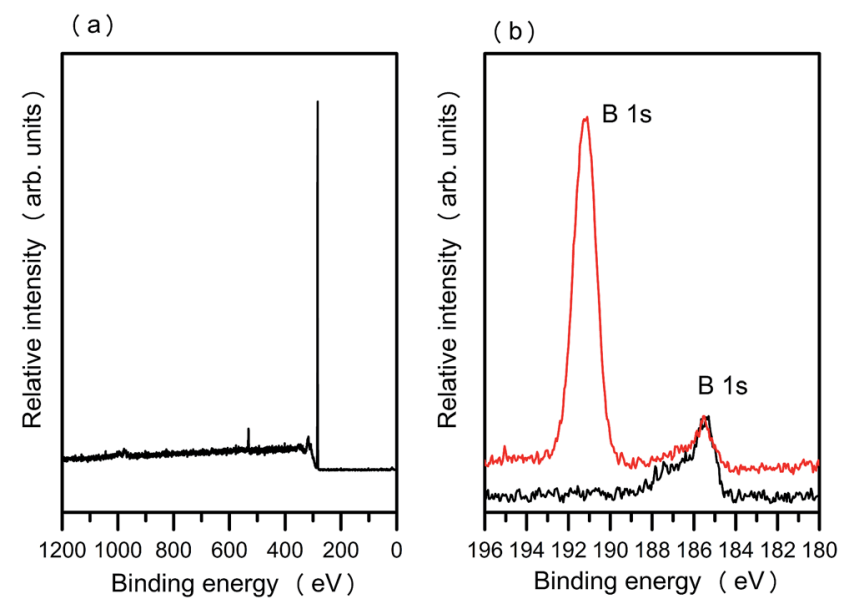

Fig. 2 (a) XPS survey spectrum of hydrogenated B:NCD. (b) Highresolution XPS spectra showing the $B$ 1s peaks for hydrogenated (black line) and arylboronic ester grafted B:NCD (red line), respectively. 
Table 1 Optimization of the Suzuki cross-coupling conditions for $\mathrm{Br}-\mathrm{BT}-\mathrm{CHO}$ and $\mathrm{Br}-\mathrm{BT}$-Rho

\begin{tabular}{|c|c|c|c|c|c|}
\hline \multirow[b]{2}{*}{ Entry } & \multirow[b]{2}{*}{ Catalyst/ligand $^{a}$} & \multirow[b]{2}{*}{ Base } & \multirow[b]{2}{*}{ Solvent } & \multicolumn{2}{|c|}{ Surface coverage $e^{b}$} \\
\hline & & & & $\mathrm{Br}-\mathrm{BT}-\mathrm{CHO}^{c}$ & Br-BT-Rho \\
\hline 1 & $\mathrm{Pd}\left(\mathrm{PPh}_{3}\right)_{4}(10 \mathrm{~mol} \%)$ & NaOAc (1 equiv.) & THF & 0.05 & 0.01 \\
\hline 2 & $\operatorname{Pd}\left(\mathrm{PPh}_{3}\right)_{4}(10 \mathrm{~mol} \%)$ & $\mathrm{Na}_{2} \mathrm{CO}_{3}$ (4 equiv.) & THF- $\mathrm{H}_{2} \mathrm{O}(5: 1)$ & 0.02 & 0.005 \\
\hline 3 & $\mathrm{Pd}(\mathrm{OAc})_{2}(5 \mathrm{~mol} \%)-\mathrm{P}(o-\mathrm{tol})_{3}(10 \mathrm{~mol} \%)$ & $\mathrm{K}_{3} \mathrm{PO}_{4}$ (5 equiv.) & THF & 0.03 & - \\
\hline 4 & $\mathrm{Pd}(\mathrm{OAc})_{2}(5 \mathrm{~mol} \%)-\mathrm{P}(o \text {-tol })_{3}(10 \mathrm{~mol} \%)$ & CsOAc ( 1 equiv.) & THF & 0.05 & - \\
\hline 5 & $\mathrm{Pd}(\mathrm{OAc})_{2}(5 \mathrm{~mol} \%)-\mathrm{P}(o \text {-tol })_{3}(10 \mathrm{~mol} \%)$ & CsF ( 1 equiv.) & THF & Not successful & - \\
\hline 6 & $\mathrm{Pd}(\mathrm{OAc})_{2}(5 \mathrm{~mol} \%)-\mathrm{P}(o-\mathrm{tol})_{3}(10 \mathrm{~mol} \%)$ & NaOAc ( 1 equiv.) & THF & 0.24 & 0.08 \\
\hline 7 & $\mathrm{Pd}(\mathrm{OAc})_{2}(3 \mathrm{~mol} \%)-\mathrm{SPhos}(3 \mathrm{~mol} \%)$ & $\mathrm{K}_{3} \mathrm{PO}_{4}$ (5 equiv.) & Dioxane- $\mathrm{H}_{2} \mathrm{O}(5: 1)$ & 0.43 & - \\
\hline 8 & $\mathrm{Pd}(\mathrm{OAc})_{2}(3 \mathrm{~mol} \%)-\mathrm{SPhos}(3 \mathrm{~mol} \%)$ & CsOAc ( 2 equiv.) & THF-MeOH $(5: 1)$ & 0.36 & 0.58 \\
\hline
\end{tabular}

${ }^{a}$ General conditions: $80^{\circ} \mathrm{C}, 18 \mathrm{~h}, 6 \mathrm{~mL}$ solvent, $100 \mu \mathrm{mol} \mathrm{Ar}-\mathrm{Br} .{ }^{b}$ The XPS S 2p intensity was used to estimate the surface coverage. ${ }^{c}$ Precursor used as a model compound.

Table 2 Optimization of the Suzuki cross-coupling conditions for Br-CPDT-CHO and Br-CPDT-Fur

\begin{tabular}{|c|c|c|c|c|c|}
\hline \multirow[b]{2}{*}{ Entry } & \multirow[b]{2}{*}{ Catalyst/ligand $^{a}$} & \multirow[b]{2}{*}{ Base } & \multirow[b]{2}{*}{ Solvent } & \multicolumn{2}{|c|}{ Surface coverage $^{b}$} \\
\hline & & & & Br-CPDT-CHO $^{c}$ & Br-CPDT-Fur \\
\hline 2 & $\mathrm{Pd}(\mathrm{OAc})_{2}(5 \mathrm{~mol} \%)-\mathrm{P}(o-\mathrm{tol})_{3}(10 \mathrm{~mol} \%)$ & NaOAc (1 equiv.) & THF & - & 0.06 \\
\hline 3 & $\mathrm{Pd}(\mathrm{OAc})_{2}(5 \mathrm{~mol} \%)-\mathrm{P}(o-\mathrm{tol})_{3}(10 \mathrm{~mol} \%)$ & CsF ( 2 equiv.) & THF-MeOH (5:1) & 0.10 & - \\
\hline 4 & $\operatorname{Pd}(\mathrm{OAc})_{2}(3 \mathrm{~mol} \%)-\mathrm{SPhos}(3 \mathrm{~mol} \%)$ & $\mathrm{K}_{3} \mathrm{PO}_{4}$ (5 equiv.) & Dioxane- $\mathrm{H}_{2} \mathrm{O}(5: 1)$ & 0.55 & - \\
\hline
\end{tabular}

${ }^{a}$ General conditions: $80^{\circ} \mathrm{C}, 18 \mathrm{~h}, 6 \mathrm{~mL}$ solvent, $100 \mu \mathrm{mol}$ Ar-Br. ${ }^{b}$ The XPS S 2p intensity was used to estimate the surface coverage. ${ }^{c}$ Precursor used as model compound.

Successful coupling was confirmed by monitoring the $\mathrm{S}$ and $\mathrm{N}$ markers present in the dye molecules by XPS (Fig. 3). To determine the surface coverage, the $\mathrm{S} 2 \mathrm{p}$ peak intensities were calibrated against the XPS 2p intensity of a dodecanethiol selfassembled monolayer (SAM) on $\mathrm{Au},{ }^{17}$ where the coverage of the latter was assumed to be $1 \mathrm{ML}$ (see Experimental). The coverages for both molecular wires as determined by this method are listed in Tables 1 and 2. When the standard catalytic system outlined in Entry $1\left(\operatorname{Pd}\left(\mathrm{PPh}_{3}\right)_{4}, \mathrm{NaOAc}, \mathrm{THF}\right)$ was used, the obtained surface loadings ( 0.01 and $0.02 \mathrm{ML}$, respectively) were relatively low as compared to the results obtained by Zhong et $a .^{17}$ There are three possible reasons for the low surface coverage. First, the relative reactivity for the Suzuki crosscoupling is known to be R-I (Zhong and co-workers used an
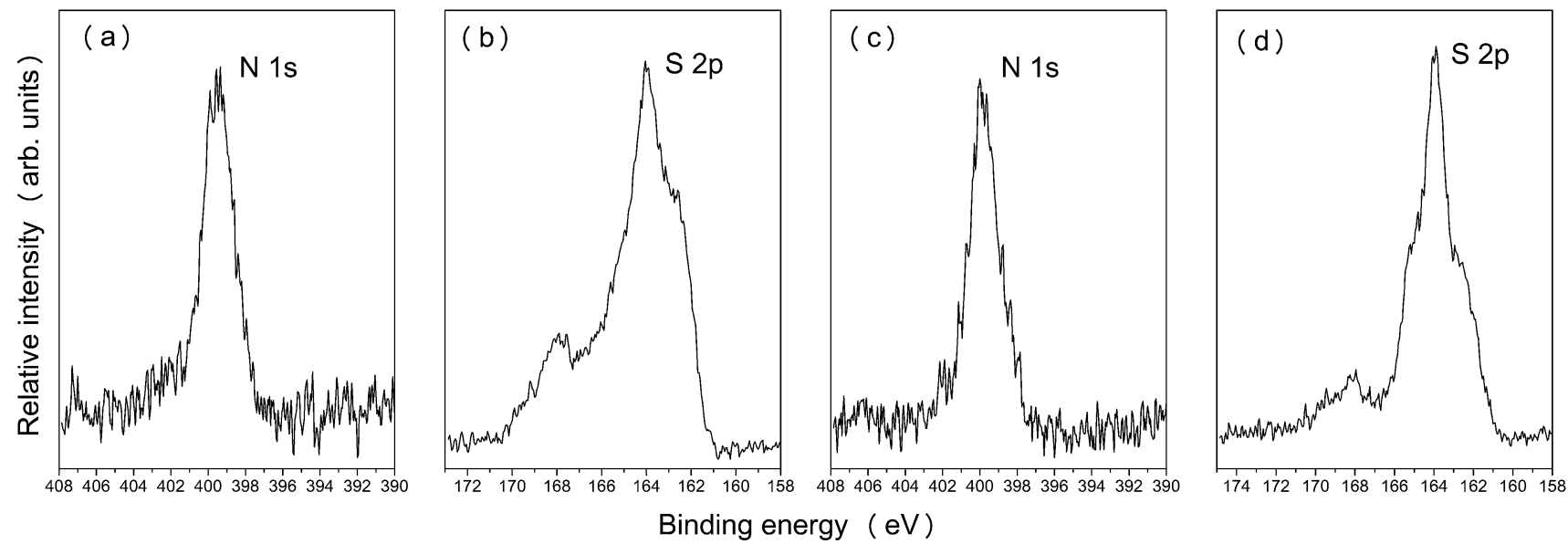

Fig. 3 XPS spectra showing the N 1s and S 2p peaks for the Br-CPDT-Fur (a and b) (Table 2, Entry 6) and Br-BT-Rho (c and d) (Table 1, Entry 8) based molecular wires ( $\mathrm{Pd}(\mathrm{OAc})_{2} / \mathrm{SPhos}$ catalytic system). 
iodinated bithiophene $)>\mathrm{R}-\mathrm{Br} \gg \mathrm{R}-\mathrm{Cl} .{ }^{21}$ Secondly, $\mathrm{Pd}\left(\mathrm{PPh}_{3}\right)_{4}$ is known to be easily degrading, even in the presence of the smallest amount of oxygen, thus reducing the coupling efficiency. ${ }^{22}$ Thirdly, for sterically demanding molecules as the two molecular wires used here, catalytic systems with electron-rich ligands are often more appropriate. ${ }^{23}$ A slightly better coverage was observed when an in situ generated Pd catalyst, via combination of tri(o-tolyl)phosphine $\left(\mathrm{P}(o \text {-tol })_{3}\right)$ and palladium(II) acetate $\left(\mathrm{Pd}(\mathrm{OAc})_{2}\right)$, was used (Entry 6, Table 1; Entry 2, Table 2). The more electron-donating tri(o-tolyl)phosphine ligand enhances the oxidative insertion of Pd into the
Ar-Br bond..$^{23}$ Moreover, the steric congestion of the ligand can also facilitate dissociation of the ligand from the Pd complex.

Over the past 20 years, the Buchwald group has made important contributions to the design of sterically hindered electron-rich biarylmonodentate phosphine ligands such as SPhos and XPhos (2-dicyclohexylphosphino-2', $4^{\prime}, 6^{\prime}$-triisopropylbiphenyl) which, when combined with catalytic amounts of $\operatorname{Pd}(0)$, enable to prepare extremely hindered biaryls via SuzukiMiyaura cross-coupling reactions in an efficient manner. ${ }^{24}$ Recently, Zhou et al. successfully applied these conditions towards extension of the CPDT chromophore. ${ }^{25}$ Triggered by the
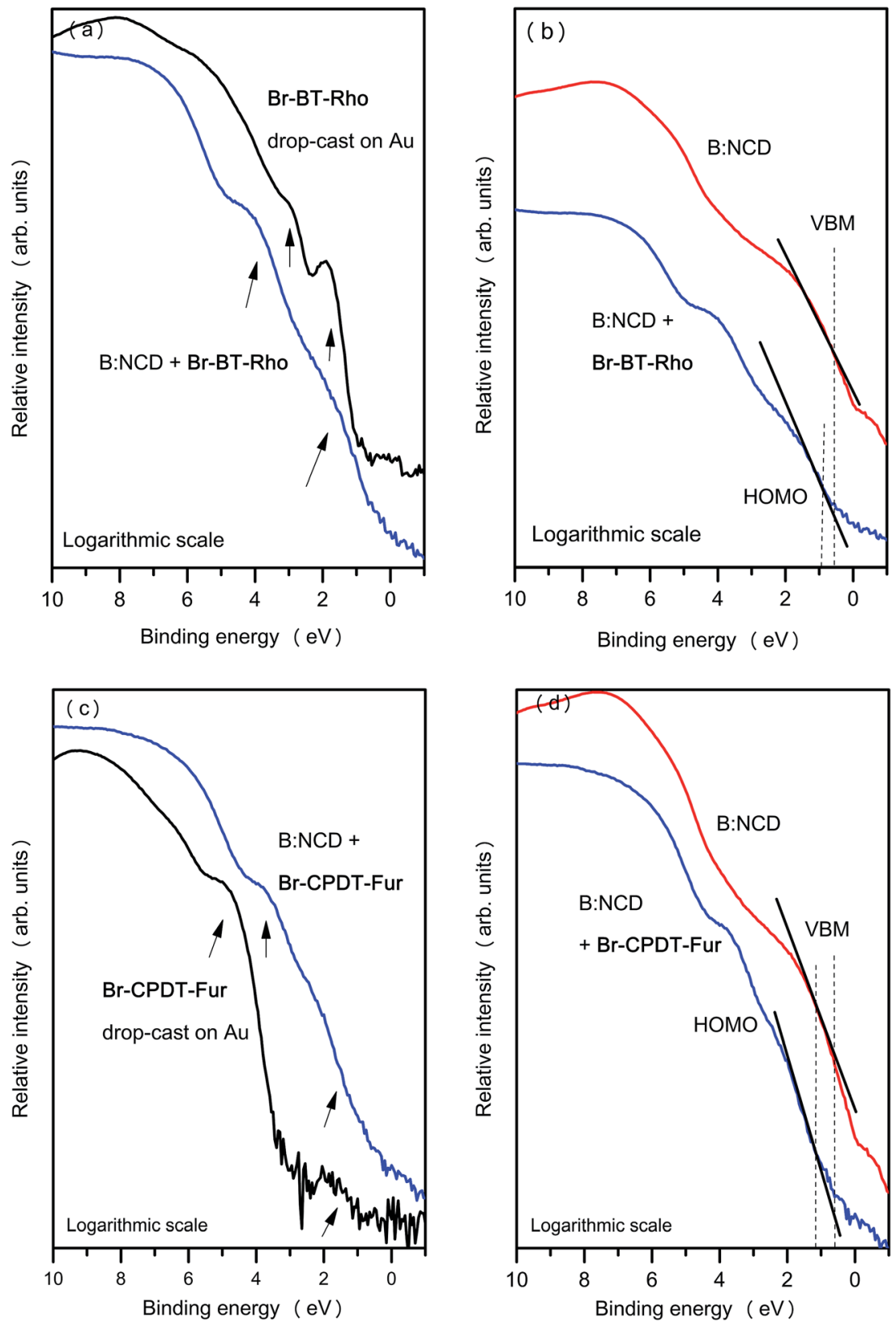

Fig. 4 (a and c) Comparison of the UPS spectra of the molecular wire-functionalized B:NCDs (blue line) and the pure molecular wires (dropcasted on an Au substrate) (black line) for (a) Br-BT-Rho and (c) Br-CPDT-Fur on an logarithmic scale. (b and d) Comparison of the UPS spectra of the molecular wire-functionalized B:NCDs (blue line) and a bare hydrogen-terminated B:NCD film (red line) for (b) Br-BT-Rho and (d) Br-CPDTFur on an logarithmic scale. Linear extrapolation of the valence band edge yields an estimate of the VBM the of B:NCD thin film. 
effectiveness of the method and the similar CPDT building blocks used, we applied this catalytic system to the Suzuki crosscoupling on the B:NCD surface. Zhou and co-workers applied a dioxane-water mixture as the reaction solvent and $\mathrm{K}_{3} \mathrm{PO}_{4}$ as a base. This catalytic system might, however, cleave our acceptor groups from the molecular wires due to hydrolysis. We thus first tested the catalytic system for two 'precursor' systems (Br-BTCHO and Br-CPDT-CHO) devoid of the respective acceptor groups. As shown in Table 1 (Entry 7) and Table 2 (Entry 4), the surface coverages increased tremendously. When the $\operatorname{Pd}(\mathrm{OAc})_{2} /$ SPhos catalyst was used in combination with CsOAc base in a water-free THF-MeOH (5:1) mixture (Entry 8, Table 1 and Entry 6 , Table 2), a comparable surface coverage was achieved. Hence, these conditions were also applied for the full molecular wire systems. As illustrated in Table 1 (Entry 8) and 2 (Entry 6), the overall coupling efficiency was noticeably higher when SPhos was used as the supporting ligand. A surface coverage of 0.58 and 0.56 ML was achieved for the Br-2T-Rho and Br-CPDT-Fur chromophores, respectively, the highest reported surface coverages so far for Suzuki cross-coupling on B:NCD films (Fig. 3). An increase in coverage of $17 \%$ is achieved despite the use of a less reactive $\mathrm{Br}-\mathrm{Ar}$ function and a more complex molecular structure (0.56 ML for Br-CPDT-Fur) as compared to the results of Zhong and co-workers (0.41 ML for 2-(dicyanovinyl)-5-iodobithiophene). ${ }^{17}$ Moreover, the Pd catalyst usage is also quite low (3 mol\%) as compared to standard $\mathrm{Pd}\left(\mathrm{PPh}_{3}\right)_{4}$, which requires a loading of $10 \mathrm{~mol} \% .^{17}$

UPS was applied to probe the electronic properties of the valence band of the functionalized B:NCD samples. Fig. 4(a) and (c) show the UPS spectra of the Br-BT-Rho and Br-CPDT-Fur functionalized B:NCDs, respectively, compared to the respective pure molecular wire systems (drop-casted on an Au substrate). When the UPS intensity is plotted on a logarithmic scale, the weak valence band feature can be distinguished. The first valence band peak for both Br-BT-Rho and Br-BT-Rho functionalized B:NCD appears around $0.9 \mathrm{eV}$. On the other hand, for Br-CPDT-Fur and Br-CPDT-Fur functionalized B:NCD, the first valence band peak appears around $1.1 \mathrm{eV}$.

To determine the HOMO energy levels of both molecular wire systems, the UPS spectra of the functionalized diamond films were compared to bare hydrogen-terminated B:NCD thin films (Fig. $4 \mathrm{~b}$ and d). By linear extrapolation of the hydrogenterminated B:NCD thin film UPS data, the position of the valence band maximum (VBM) of diamond with respect to its Fermi level can be determined. It is approximately $0.6 \mathrm{eV}$ below the (surface) Fermi level. Previous studies have shown that $E_{\mathrm{f}}$ VBM is $0.25 \mathrm{eV}$ in bulk B-doped diamond. However, it can increase up to $0.7 \mathrm{eV}$ at the surface of a clean $\mathrm{H}$-terminated diamond. ${ }^{26-29}$ Accordingly, the HOMO levels of the Br-BT-Rho and Br-CPDT-Fur functionalized diamond samples lie 0.3 and $0.5 \mathrm{eV}$ below the VBM of B:NCD, respectively. These energy differences have implications on the possibility for hole transport between the B:NCD thin film and the functionalized molecular wires. Based on the principle of charge transfer in dye-sensitized solar cells with $p$-semiconducting photocathode ( $p$-DSSCs), upon photogeneration of an exciton, the electron is transferred to an acceptor site and subsequently to the oxidized form of the electrolyte redox mediator. In turn, the hole is transferred from the donor site to the semiconductor electrode. Hence, a good match between the HOMO of the donor molecule and the valence band of the electrode is important for efficient hole injection. For B:NCD, the VBM is situated rather close to the HOMO of both molecular wires, which should favor hole injection from the light-harvesting chromophores to the B:NCD thin film. ${ }^{17,29}$

As a proof of concept, photoelectrochemical measurements were performed using either a hydrogen-terminated, Br-CPDTFur or Br-BT-Rho functionalized B:NCD film as the working electrode in a standard three-electrode electrochemical system (Fig. 5). After equilibration in darkness, the light source was switched on and off approximately every $10 \mathrm{~s}$ for several cycles. At time $=0$, the electrode was in dark, and each light-on triggered the cathodic photocurrent. The process was fully reversible, and was stopped at time $\approx 300 \mathrm{~s}$, when the electrode was

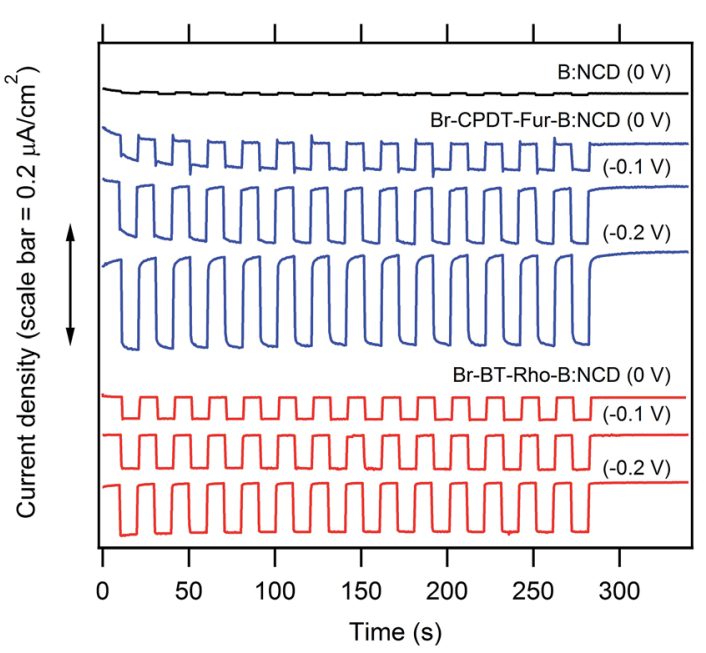

Fig. 5 Photocurrent response of B:NCD (black line), Br-CPDT-Fur$\mathrm{B}: \mathrm{NCD}$ (blue lines), and Br-BT-Rho-B:NCD (red lines) electrodes in a 5 $\mathrm{mM}$ methyl viologen solution (in $0.1 \mathrm{M} \mathrm{Na}_{2} \mathrm{SO}_{4}$ ) at varying bias (vs. $\mathrm{Ag}$ / $\mathrm{AgCl})$. White light illumination by a Xe-lamp $\left(15 \mathrm{~mW} \mathrm{~cm}^{-2}\right)$. Curves are offset for clarity, but the intensity scale is identical in all cases.

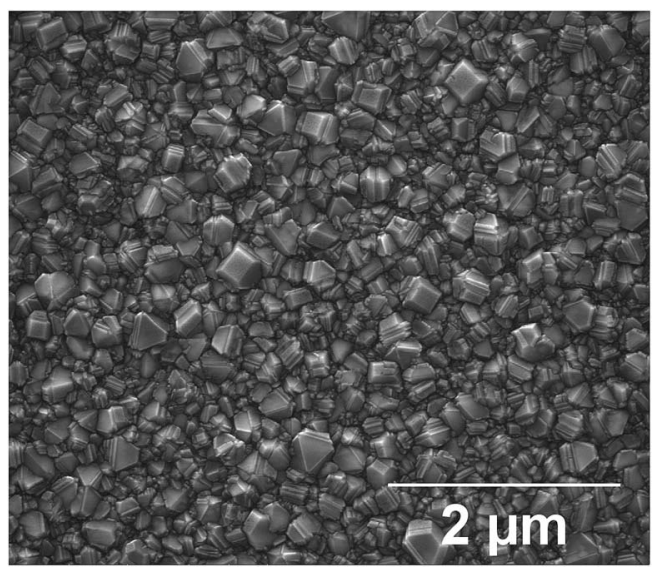

Fig. 6 Typical SEM image of a B:NCD film. 
relaxed again in dark. We observed an increased photocurrent intensity for both molecular wire functionalized B:NCD electrodes as compared to the control system. In accord with previous work, ${ }^{17}$ negative bias enhances the photocurrent considerably. This agrees well with the mechanism that, upon light generation of electron-hole pairs in the molecular wires, the separated electrons flow toward the $\mathrm{MV}^{2+}$ (dimethyl viologen) electron carrier and the holes toward the B:NCD electrode (at negative bias). ${ }^{\mathbf{1 6 , 1 7}}$

Our photocurrents are comparable to those reported earlier for similar systems: Zhong et al. ${ }^{16}$ observed a photocurrent of $c a$. $150 \mathrm{nA} \mathrm{cm}{ }^{-2}$ under white light (150 W halogen lamp) illumination of B:NCD sensitized by dicyanovinyl-bithiophene and $\mathrm{C}_{60}$-bithophene. Later on, the same group reported $c a$. 4-6 $\mu \mathrm{A}$ $\mathrm{cm}^{-2}$ under 1 sun illumination (AM1.5G; $100 \mathrm{~mW} \mathrm{~cm}{ }^{-2}$ ). ${ }^{17}$ In general, photocurrents on sensitized diamond electrodes are very small compared to those observed for the state-of-art $n$ DSSCs with titania photoanode $\left(\approx 20 \mathrm{~mA} \mathrm{~cm}^{-2}\right.$ at 1 sun $)$. Among other reasons, the difference can be rationalized in terms of surface morphology of the aforementioned semiconductor photoelectrodes. Early works on flat titania surface, sensitized with $\mathrm{Ru}$-bipyridine complexes, reported photocurrents of several nA under white light $(450<\lambda / \mathrm{nm}<650)$ illumination from a $150 \mathrm{~W}$ Xe-lamp. ${ }^{30}$ In principle, the flat electrode cannot deliver external quantum efficiencies larger than $\approx 0.3 \%$, whereas mesoporous electrodes can give values exceeding $90 \%$ for the same dye/electrolyte systems. ${ }^{31}$ The B:NCD films made by CVD are usually quite compact, with double-layer capacitances approaching those of flat surfaces $\left(c a .3 \mu \mathrm{F} \mathrm{cm}^{-2}\right) .{ }^{32}$ Also our SEM image shown below (Fig. 6) confirms quite dense packing of the diamond crystals without any noticeable mesoporosity. Hence, surface engineering of the B:NCD photoanode is a straightforward task in the future development of diamondbased $p$-DSSCs.

\section{Conclusions}

In summary, we have demonstrated that a proper choice of the catalytic system used for Suzuki cross-coupling can effectively increase the coupling efficiency, also on a diamond surface. Best results, leading to unprecedented surface loadings, were obtained for the $\mathrm{Pd}(\mathrm{OAc})_{2} / \mathrm{SPhos}$ combination. The resulting B:NCD films decorated with light-harvesting molecular dyes can potentially be applied for 'all-carbon' photovoltaic applications. Preliminary photoelectrochemical measurements using the novel molecular wire systems show photocurrent generation. More detailed studies concerning full devices and quantum efficiencies will be carried out and reported in near future.

\section{Experimental}

\section{Chemical reagents}

Commercially available chemicals were purchased in their purest grade available and used without further purification. Sodium nitrite, sodium carbonate, sodium acetate, cesium acetate, cesium fluoride, potassium phosphate, palladium(II) acetate, 4-aminophenylboronic acid pinacol ester, rhodanine-3- acetic acid, tetrakis(triphenylphosphine)palladium(0), and tri(o-tolyl)phosphine were purchased from Sigma-Aldrich. 5Bromo-5'-formyl-2,2'-bithiophene was purchased from TCI Europe N.V. 2-Dicyclohexylphosphino-2',6'-dimethoxybiphenyl (SPhos) was purchased from Acros Organics. All solvents used for reactions and rinsing were of HPLC grade, unless otherwise stated. Water used for rinsing and electrochemical work was made with Type 1 Ultrapure water by Sartorius stedium Biotech.

\section{Synthesis and characterization}

NMR chemical shifts $(\delta)$ were determined relative to the residual $\mathrm{CHCl}_{3}$ absorption $(7.26 \mathrm{ppm})$ or the ${ }^{13} \mathrm{C}$ resonance shift of $\mathrm{CDCl}_{3}$ (77.16 ppm). UV-Vis absorption spectra were recorded with an Agilent Cary 500 Scan UV-Vis-NIR spectrometer in a continuous run from 200 to $800 \mathrm{~nm}$ at a scan rate of $600 \mathrm{~nm} \min ^{-1}$. Electrochemical measurements were performed with an Eco Chemie Autolab PGSTAT 30 potentiostat/ galvanostat using a three-electrode microcell equipped with a $\mathrm{Pt}$ wire working electrode, a Pt wire counter electrode and a $\mathrm{Ag} /$ $\mathrm{AgNO}_{3}$ reference electrode (Ag wire dipped in a solution of 0.01 $\mathrm{M} \mathrm{AgNO}_{3}$ and $0.1 \mathrm{M} \mathrm{NBu}_{4} \mathrm{PF}_{6}$ in anhydrous MeCN). Samples were prepared in anhydrous $\mathrm{CH}_{2} \mathrm{Cl}_{2}$ containing $0.1 \mathrm{M} \mathrm{NBu}_{4} \mathrm{PF}_{6}$ and ferrocene was used as an internal standard. The respective products were dissolved in the electrolyte solution and degassed with argon prior to each measurement. To prevent air from entering the system, the experiments were carried out under argon. Cyclic voltammograms were recorded at a scan rate of $50 \mathrm{mV} \mathrm{s}^{-1}$. The HOMO-LUMO energy levels of Br-CPDTFur were determined using $\mathrm{CV}$ data. For the conversion of $\mathrm{V}$ to $\mathrm{eV}$, the onset potentials of the first oxidation/reduction peaks were used and referenced to ferrocene/ferrocenium, which has an ionization potential of $-4.98 \mathrm{eV} v s$. vacuum. This correction factor is based on a value of $0.31 \mathrm{eV}$ for $\mathrm{Fc} / \mathrm{Fc}^{+} v s$. $\mathrm{SCE}^{33 a}$ and a value of $4.68 \mathrm{eV}$ for $\mathrm{SCE}$ vs. vacuum: ${ }^{33 b}$ $E_{\mathrm{HOMO} / \mathrm{LUMO}}(\mathrm{eV})=-4.98-E_{\text {onset ox } / \text { red }}^{\mathrm{Ag} / \mathrm{AgNO}_{3}}(\mathrm{~V})+E_{\text {onset Fc } / \mathrm{Fc}^{+}}^{\mathrm{Ag} / \mathrm{AgNO}_{3}}(\mathrm{~V}) . \quad$ To estimate the optical HOMO-LUMO gap, the wavelength at the intersection of the tangent line drawn at the low energy side of the (solution) absorption spectrum with the $x$-axis was used $\left(\Delta E_{\text {opt }}(\mathrm{eV})=1240 /(\right.$ wavelength in $\left.\mathrm{nm})\right)$.

4,4-Diethyl-4H-cyclopenta[1,2- $\left.b: 5,4-b^{\prime}\right]$ dithiophen-2-carboxaldehyde (CPDT-CHO) (2). To a cold solution $\left(0{ }^{\circ} \mathrm{C}\right)$ of 4,4 diethyl-4H-cyclopenta[1,2- $\left.b: 5,4-b^{\prime}\right]$ dithiophene $^{20 b}$ (1) (359 mg, $1.53 \mathrm{mmol})$ in 1,2-dichloroethane $(4.5 \mathrm{~mL})$ and DMF $(140 \mu \mathrm{L})$, $\mathrm{POCl}_{3}(140 \mu \mathrm{L})$ was added under nitrogen. After $4 \mathrm{~h}$ at this temperature, a saturated NaOAc solution $(10 \mathrm{~mL})$ was added. The mixture was stirred at room temperature for $2 \mathrm{~h}$. The crude product was extracted into $\mathrm{CH}_{2} \mathrm{Cl}_{2}$. The organic layer was washed with water and brine. After drying with $\mathrm{MgSO}_{4}$ and filtration, the solvent was removed to afford the product as colourless oil in a quantitative way $(400 \mathrm{mg}) .{ }^{1} \mathrm{H}$ NMR $\left(\mathrm{CDCl}_{3}\right)$ : $0.61\left(\mathrm{t}, 6 \mathrm{H}, J=7.4 \mathrm{~Hz}, \mathrm{CH}_{2} \mathrm{CH}_{3}\right), 1.95\left(\mathrm{~m}, 4 \mathrm{H}, \mathrm{CH}_{2} \mathrm{CH}_{3}\right), 7.00$ (d, $1 \mathrm{H}, J=4.8 \mathrm{~Hz}), 7.43(\mathrm{~d}, 1 \mathrm{H}, J=4.8 \mathrm{~Hz}), 7.58(\mathrm{~s}, 1 \mathrm{H}), 9.84(\mathrm{~s}, 1 \mathrm{H}$, $\mathrm{CHO})$.

6-Bromo-4,4-diethyl-4H-cyclopenta[1,2-b:5,4- $\left.b^{\prime}\right]$ dithiophen2-carboxaldehyde (Br-CPDT-CHO) (3). To a cold solution $\left(0{ }^{\circ} \mathrm{C}\right)$ of CPDT-CHO 2 (410 mg, $1.56 \mathrm{mmol}$ ) in THF (50 mL), NBS (345 
mg, 1.24 equiv.) was added under a nitrogen atmosphere. The reaction mixture was warmed gently to room temperature and stirred further for $5 \mathrm{~h}$. Then, water $(50 \mathrm{~mL})$ was added and the product was extracted with $\mathrm{CH}_{2} \mathrm{Cl}_{2}$. The organic phase was dried $\left(\mathrm{MgSO}_{4}\right)$ and the solvent was removed to afford the product as a colourless oil in a quantitative way $(530 \mathrm{mg}) .{ }^{1} \mathrm{H} \mathrm{NMR}\left(\mathrm{CDCl}_{3}\right)$ : $0.61\left(\mathrm{t}, 6 \mathrm{H}, J=7.4 \mathrm{~Hz}, \mathrm{CH}_{2} \mathrm{CH}_{3}\right), 1.92\left(\mathrm{~m}, 4 \mathrm{H}, \mathrm{CH}_{2} \mathrm{CH}_{3}\right), 7.02(\mathrm{~s}$, 1H), 7.57 (s, 1H), 9.84 (s, 1H, CHO).

$(E)-2-\left\{4-\left[2-\left(6-B r o m o-4,4-d i e t h y l-4 H\right.\right.\right.$-cyclopenta[1,2-b:5,4- $\left.b^{\prime}\right]$ dithiophen-2-yl)vinyl]-3-cyano-5,5-dimethylfuran-2(5H)-ylidene\}malononitrile (Br-CPDT-Fur). 6-Bromo-4,4-diethyl-4H-cyclopenta[1,2-b:5,4- $\left.b^{\prime}\right]$ dithiophene-2-carbaldehyde (3) (533 mg, 1.56 $\mathrm{mmol}$ ) and 2-(3-cyano-4,5,5-trimethylfuran-2 $(5 \mathrm{H})$-ylidene)malononitrile $(4)^{34}$ (330 $\mathrm{mg}, 1.56 \mathrm{mmol}$ ) were dissolved in ethanol (10 $\mathrm{mL}$ ). Piperidine ( 2 drops) was added and the reaction mixture was heated at reflux overnight. The dark reaction mixture was cooled down to room temperature and a precipitate was formed, which was filtered off and recrystallized from an ethanol-water mixture to give the product as greenish-yellow crystals (dark blue in solution) $(478 \mathrm{mg}, 58 \%)$. m.p. $>250{ }^{\circ} \mathrm{C} .{ }^{1} \mathrm{H} \mathrm{NMR}\left(\mathrm{CDCl}_{3}\right)$ : $0.61\left(\mathrm{t}, 6 \mathrm{H}, J=7.4 \mathrm{~Hz}, \mathrm{CH}_{2} \mathrm{CH}_{3}\right), 1.74\left(\mathrm{~s}, 6 \mathrm{H}, \mathrm{CH}_{3}\right), 1.93(\mathrm{~m}, 4 \mathrm{H}$, $\left.\mathrm{CH}_{2} \mathrm{CH}_{3}\right), 6.59(\mathrm{~d}, 1 \mathrm{H}, J=15.6 \mathrm{~Hz},-\mathrm{CH}=\mathrm{CH}-), 7.04(\mathrm{~s} 1 \mathrm{H}), 7.34$ $(\mathrm{s}, 1 \mathrm{H}), 7.90(\mathrm{~d}, 1 \mathrm{H}, J=15.8 \mathrm{~Hz},-\mathrm{CH}=\mathrm{CH}-) .{ }^{13} \mathrm{C} \mathrm{NMR}\left(\mathrm{CDCl}_{3}\right)$ : 9.3, 26.7, 30.3, 56.09, 56.12, 77.4, 95.6, 97.1, 110.5, 111.5, 111.7, 118.2 , 125.3, 136.7, 140.6, 141.0, 147.6, 158.8, 161.4, 173.0, 176.1. UV-Vis $\left(\mathrm{CHCl}_{3}\right): \lambda_{\max }=585 \mathrm{~nm}, \varepsilon=73100 \mathrm{~L} \mathrm{~mol}^{-1} \mathrm{~cm}^{-1}$, $\Delta E_{\text {opt }}=1.85 \mathrm{eV}$.

Diamond growth. Polycrystalline boron-doped nanocrystalline diamond (B:NCD) thin films (150 nm in thickness) were grown by microwave plasma-enhanced chemical vapour deposition (CVD) from methane/hydrogen mixtures $\left(1 \% \mathrm{CH}_{4}\right)$ in an ASTeX 6500 reactor. The substrates used were fused silica $(1 \mathrm{~cm}$ $\times 1 \mathrm{~cm}$ ). The growth conditions used were as follows: substrate temperature $700-900{ }^{\circ} \mathrm{C}$, total gas flow $500 \mathrm{sccm}$, total pressure in the reactor 30 Torr, microwave power $3500 \mathrm{~W}$. Trimethylborane gas was added during the growth with a ratio of $10000 \mathrm{ppm} \mathrm{B} / \mathrm{C}$ to $\mathrm{CH}_{4}$ to ensure good electrical conductivity. ${ }^{1 b}$ Based on previous experiments, ${ }^{35}$ this ratio corresponds to a boron film concentration $10^{21} \mathrm{~cm}^{-3}$. Sheet resistance $\left(R_{\mathrm{s}}\right)$, as measured by a four-point probe measurement, was $207 \Omega \mathrm{sq}^{-1}$, which agrees well with the typical value for B:NCD grown under these conditions. ${ }^{3}$ Prior to the diamond growth, the fused silica substrates were cleaned for 15 min each in RCA $1\left(30 \% \mathrm{NH}_{3}+\right.$ $\left.30 \% \mathrm{H}_{2} \mathrm{O}_{2}+\mathrm{H}_{2} \mathrm{O} ; 1: 1: 5\right)$ and RCA $2\left(37 \% \mathrm{HCl}+30 \% \mathrm{H}_{2} \mathrm{O}_{2}+\right.$ $\left.\mathrm{H}_{2} \mathrm{O} ; 1: 1: 5\right)$ solutions at $90{ }^{\circ} \mathrm{C}$. Following this, the cleaned fused silica substrates were seeded with nanodiamond powder in water to improve the nucleation density. After deposition, the diamond samples were allowed to cool down in the reactor for 30 min under vacuum. To remove any graphitic layers, the asdeposited diamond films were boiled in an acidic mixture of $99 \% \mathrm{H}_{2} \mathrm{SO}_{4}+30 \% \mathrm{HNO}_{3}(3: 1)$ at $90{ }^{\circ} \mathrm{C}$ for $30 \mathrm{~min}$. After rinsing and sonicating with plenty of deionized water, the diamond samples were subjected to hydrogenation. Fig. 6 displays a scanning electron microscopy (SEM) image of a typical as-grown B:NCD thin film.

Hydrogenation. Hydrogenation was performed using the same PECVD reactor (ASTeX 6500). To create a hydrogen terminated surface, all diamond samples were treated with hydrogen plasma under the following conditions: (i) $500 \mathrm{sccm}$ hydrogen flux, 30 Torr reactor pressure with a $3500 \mathrm{~W}$ microwave power for $2 \mathrm{~min}$, (ii) $500 \mathrm{sccm}$ hydrogen flux, 15 Torr reactor pressure with a $2500 \mathrm{~W}$ microwave power for $5 \mathrm{~min}$, (iii) at the end of the plasma treatment, the microwave power was switched off and the samples were allowed to cool down under hydrogen flux for $40 \mathrm{~min}$.

Diazonium coupling. The functionalization of the diamond surfaces started with diazonization of the targeted aniline (4aminophenylboronic acid pinacol ester) followed by electrochemical reduction of the in situ generated diazonium salt by cyclic voltammetry (Scheme 1). ${ }^{\mathbf{1 6}}$ The electrografting reaction was performed with an Autolab PGSTAT30 potentiostat (Eco Chemie B.V.) and controlled by the GPES Program. A onecompartment electrochemical cell with three-electrode configuration was used. The working electrode was a hydrogenterminated B:NCD film. Platinum wire and $\mathrm{Ag} / \mathrm{AgCl} / \mathrm{KCl}_{\text {(sat) }}$ electrodes were used as counter and reference electrodes, respectively. Half of the diamond sample was immersed in the reaction solution for larger area functionalization. As stated above, $5 \mathrm{mM}$ of 4-aminophenylboronic acid pinacol ester was diazotized with an equimolar amount of $\mathrm{NaNO}_{2}$ in a $\left(\mathrm{N}_{2}\right.$ gas purged) $0.5 \mathrm{M} \mathrm{HCl}$ solution, which was directly used for $\mathrm{CV}$ scanning with a potential from +0.5 to $-0.8 \mathrm{~V}(v s$. $\mathrm{Ag} / \mathrm{AgCl})$ at a scan rate of $100 \mathrm{mV} \mathrm{s}{ }^{-1}$ for 5 scans. ${ }^{16}$ After the modifications, the substrates were sequentially rinsed and sonicated in ultrapure water, THF and $n$-hexane to remove any physisorbed molecules.

Suzuki cross-coupling. All preparations for the Suzuki crosscoupling reactions were performed in a glove box. To achieve the highest possible surface coverage, the most efficient conditions were pursued. In general, a $15 \mathrm{~mL}$ ACE pressure tube (Sigma Aldrich) containing a magnetic stirring bar and the functionalized diamond film was charged with the dye (Br-BTCHO/Br-BT-Rho/Br-CPDT/Br-CPDT-Fur), Pd catalyst, base and solvent. The resulting mixture was then heated at $80^{\circ} \mathrm{C}$ for $18 \mathrm{~h}$. Detailed information on the catalyst systems is provided in Tables 1 and 2 .

X-ray/ultraviolet photoelectron spectroscopy. Photoemission experiments were carried out using a Scienta ESCA 200 spectrometer in ultrahigh vacuum with a base pressure of $1 \times 10^{-10}$ mbar. The measurement chamber is equipped with a monochromatic $\mathrm{Al} \mathrm{K} \alpha \mathrm{X}$-ray source and He discharge lamp providing photons with $1486.6 \mathrm{eV}$ for XPS and $21.22 \mathrm{eV}$ for UPS, respectively. The XPS experimental conditions were set so that the full width at half maximum of the clean $\mathrm{Au} 4 \mathrm{f}_{7 / 2}$ line was $0.65 \mathrm{eV}$. The total energy resolution of the measurements in UPS, determined by the Fermi edge of clean gold, is about $0.1 \mathrm{eV}$. All spectra were measured at a photoelectron take-off angle of $0^{\circ}$ normal emission. The UPS spectra have been corrected for the contributions from $\mathrm{He}$ I satellites radiation.

The surface coverage with the thiophene moieties was estimated using the same method as used in ref. 17. This is done by calibrating the XPS S 2p signal of the thiophene moieties against the measured XPS S 2p intensity of a dodecanethiol SAM on $\mathrm{Au}$, where the coverage of the latter was assumed to be $100 \%$ 


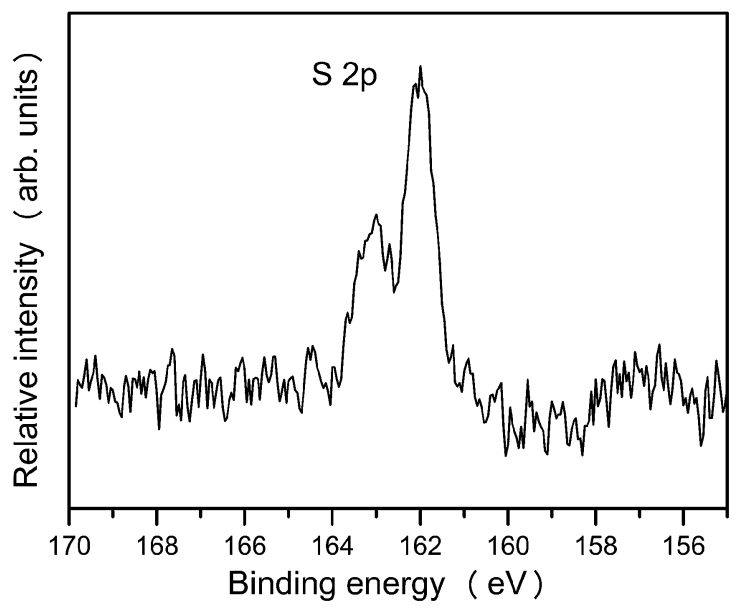

Fig. 7 XPS spectrum showing the S $2 p$ signal of dodecanethiol on a Au surface.

(1 ML) (Fig. 7). Several samples of dodecanethiol SAMs were prepared on $\mathrm{Au}$, i.e. at different functionalization times, to make sure the same S 2p signal was obtained by XPS. The $S$ intensity in dodecanethiol has been corrected for the attenuation factor due to the carbon chain.

$$
\text { Attenuation factor }=\exp \left(\frac{-n d_{\mathrm{c}}}{\lambda_{\mathrm{s}} \cos \theta}\right)=0.71
$$

$n=12$ is the number of carbon atoms in the alkyl chain, $d_{\mathrm{c}}=1.1$ $\AA$ is the length of one methylene group (1.27 $\AA$ ) at a tilt angle of $30^{\circ}$ to the surface normal, $\theta$ is the angle made by the electron energy analyzer to the surface normal, and $\lambda_{\mathrm{s}}=9.0+0.022$ $\mathrm{KE}) .{ }^{36}$ All samples were measured with short collection time and on several different spots to avoid any beam damage. However, single-collected S2p data are shown here.

Photoelectrochemical measurements. Photoelectrochemical measurements were performed in a Ar-saturated $0.1 \mathrm{M} \mathrm{Na}_{2} \mathrm{SO}_{4}$ solution containing $5 \mathrm{mM}$ methyl viologen $\left(\mathrm{MV}^{2+}\right)$ as an electron carrier in a three-electrode glass cell equipped with a quartz optical window for illumination of the B:NCD working electrode. The counter electrode was platinum and the reference electrode was $\mathrm{Ag} / \mathrm{AgCl}$ (sat. $\mathrm{KCl}$ ). The glass cell was placed in a dark room and controlled by a potentiostat (Autolab, Ecochemie, B.V. with GPES-4 software). The white light source was an Oriel Xenon lamp, model 6269. The incident light intensity was focused and calibrated with a standard Si photodiode (PV Measurements, Inc. USA). The area of the B:NCD samples exposed to light was $c a .0 .85 \mathrm{~cm}^{2}$ and the incident white light intensity was $15 \mathrm{~mW} \mathrm{~cm}^{-2}$ (which is roughly $0.15 \mathrm{sun}$ ).

\section{Acknowledgements}

This work was financially supported by the Special Research Fund of Hasselt University, the Research Foundation Flanders (FWO) (G.0555.10N), and the EU FP7 Collaborative Project "MOLESOL" (no. 256617). X.L. acknowledges support from The Swedish Research Council Linnaeus grant LiLi-NFM. L.K. acknowledges support from the Grant Agency of the Czech
Republic (contract no. 13-37383S). We thank Huguette Penxten for the cyclic voltammetry measurements.

\section{Notes and references}

1 (a) O. Williams and M. Nesladek, in Physics and Applications of CVD Diamond, ed. S. Koizumi, C. Nebel and M. Nesladek, Wiley-VCH, Weinheim, Germany, 2008; (b) S. D. Janssens, P. Pobedinskas, J. Vacik, V. Petrakova, B. Ruttens, J. D'Haen, M. Nesladek, K. Haenen and P. Wagner, New J. Phys., 2011, 13, 083008.

2 O. A. Williams, M. Nesladek, M. Daenen, S. Michaelson, A. Hoffman, E. Osawa, K. Haenen and R. B. Jackman, Diamond Relat. Mater., 2008, 17, 1080.

3 C. H. Y. X. Lim, Y. L. Zhong, S. Janssens, M. Nesladek and K. P. Loh, Adv. Funct. Mater., 2010, 20, 1313.

4 (a) R. S. Balmer, J. R. Brandon, S. L. Clewes, H. K. Dhillon, J. M. Dodson, I. Friel, P. N. Inglis, T. D. Madgwick, M. L. Markham, T. P. Mollart, N. Perkins, G. A. Scarsbrook, D. J. Twitchen, A. J. Whitehead, J. J. Wilman and S. M. Woollard, J. Phys.: Condens. Matter, 2009, 21, 36422; (b) A. Kirste, G. Schnakenburg, F. Stecker, A. Fischer and S. R. Waldvogel, Angew. Chem., Int. Ed., 2010, 49, 971; (c) Q. Wang, P. Subramanian, M. S. Li, W. S. Yeap, K. Haenen, Y. Coffinier, R. Boukherroub and S. Szunerits, Electrochem. Commun., 2013, 34, 286; (d) S. Inagi, H. Nagai, I. Tomita and T. Fuchigami, Angew. Chem., Int. Ed., 2013, 52, 6616; (e) T. L. Read, E. Bitziou, M. B. Joseph and J. V. Macpherson, Anal. Chem., 2014, 86, 367; (f) K. Nakata, T. Ozaki, C. Terashima, A. Fujishima and Y. Einaga, Angew. Chem., Int. Ed., 2014, 53, 871.

5 X. Y. Wang, E. C. Landis, R. Franking and R. J. Hamers, Acc. Chem. Res., 2010, 43, 1205.

6 X. Wang, S. Kurihara, M. Hasegawa, A. R. Ruslinda and H. Kawarada, Jpn. J. Appl. Phys., 2012, 51, 090125.

7 D. Belanger and J. Pinson, Chem. Soc. Rev., 2011, 40, 3995.

$8 \mathrm{~J}$. Lahann, in Click Chemistry for Biotechnology and Materials Science, ed. J. Lahann, John Wiley \& Sons Ltd., West Sussex, 2009, pp. 1-8.

9 N. Miyaura and A. Suzuki, Chem. Rev., 1995, 95, 2457.

10 P. Bujak, I. Kulszewicz-Bajer, M. Zagorska, V. Maurel, I. Wielgus and A. Pron, Chem. Soc. Rev., 2013, 42, 8895.

11 A. Pron, P. Gawrys, M. Zagorska, D. Djurado and R. Demadrille, Chem. Soc. Rev., 2010, 39, 2577.

12 (a) J. C. Bijleveld, M. Shahid, J. Gilot, M. M. Wienk and R. A. J. Janssen, Adv. Funct. Mater., 2009, 19, 3262; (b) D. C. Watters, H. Yi, A. J. Pearson, J. Kingsley, A. Iraqi and D. Lidzey, Macromol. Rapid Commun., 2013, 34, 1157.

13 W. Wu, L. Huang, L. Xiao, Q. Huang, R. Tang, C. Ye, J. Qin and Z. Li, RSC Adv., 2012, 2, 6520.

14 (a) F. Cheng and A. Adronov, Chem. Mater., 2006, 18, 5389; (b) J. Gao, F. Bao, Q. Zhu, Z. Tan, T. Chen, H. Cai, C. Zhao, Q. Cheng, Y. Yang and R. Ma, Polym. Chem., 2013, 4, 1672.

15 T. Hasobe, H. Imahori, H. Yamada, T. Sato, K. Ohkubo and S. Fukuzumi, Nano Lett., 2003, 3, 409.

16 Y. L. Zhong, K. P. Loh, A. Midya and Z. K. Chen, Chem. Mater., 2008, 20, 3137. 
17 Y. L. Zhong, A. Midya, Z. Ng, Z. K. Chen, M. Daenen, M. Nesladek and K. P. Loh, J. Am. Chem. Soc., 2008, 130, 17218.

18 W. S. Yeap, S. Chen and K. P. Loh, Langmuir, 2009, 25, 185.

19 (a) J. Peet, J. Y. Kim, N. E. Coates, W. L. Ma, D. Moses, A. J. Heeger and G. C. Bazan, Nat. Mater., 2007, 6, 497; (b) R. Li, J. Liu, N. Cai, M. Zhang and P. Wang, J. Phys. Chem. $B$, 2010, 114, 4461; (c) H. N. Tsao, D. M. Cho, I. Park, M. R. Hansen, A. Mavrinskiy, D. Y. Yoon, R. Graf, W. Pisula, H. W. Spiess and K. Müllen, J. Am. Chem. Soc., 2011, 133, 2605; (d) S. Van Mierloo, A. Hadipour, M.-J. Spijkman, N. Van den Brande, B. Ruttens, J. Kesters, J. D'Haen, G. Van Assche, D. M. de Leeuw, T. Aernouts, J. Manca, L. Lutsen, D. Vanderzande and W. Maes, Chem. Mater., 2012, 24, 587; (e) P. Gao, H. N. Tsao, M. Graetzel and M. K. Nazeeruddin, Org. Lett., 2012, 14, 4330; $(f)$ M. Marszalek, S. Nagane, A. Ichake, R. Humphry-Baker, V. Paul, S. M. Zakeeruddin and M. Grätzel, RSC Adv., 2013, 3, 7921; (g) J. H. Delcamp, Y. Shi, J.-H. Yum, T. Sajoto, E. Dell'Orto, S. Barlow, M. K. Nazeeruddin, S. R. Marder and M. Graetzel, Chem.-Eur. J., 2013, 19, 1819.

20 (a) W. Vanormelingen, P. Verstappen, V. Maes, D. Bevk, L. Lutsen, D. Vanderzande and W. Maes, Synlett, 2013, 24, 2389; (b) S. Van Mierloo, P. J. Adriaensens, W. Maes, L. Lutsen, T. J. Cleij, E. Botek, B. Champagne and D. J. Vanderzande, J. Org. Chem., 2010, 75, 7202.

21 A. Suzuki, Chem. Commun., 2005, 4759.

22 (a) K. L. Billingsley, T. E. Barder and S. L. Buchwald, Angew. Chem., Int. Ed., 2007, 46, 5359; (b) F.-S. Han, Chem. Soc. Rev., 2013, 42, 5270.

23 T. E. Barder, S. D. Walker, J. R. Martinelli and S. L. Buchwald, J. Am. Chem. Soc., 2005, 127, 4685.

24 J. F. Hartwig, Acc. Chem. Res., 2008, 41, 1534.
25 D. F. Zhou, N. Cai, H. J. Long, M. Zhang, Y. H. Wang and P. Wang, J. Phys. Chem. C, 2011, 115, 3163.

26 C. Bandis and B. B. Pate, Phys. Rev. B: Condens. Matter Mater. Phys., 1995, 52, 12056.

27 L. Diederich, O. M. Küttel, P. Aebi and L. Schlapbach, Surf. Sci., 1998, 418, 219.

28 F. J. Himpsel, J. F. van der Veen and D. E. Eastman, Phys. Rev. B: Condens. Matter Mater. Phys., 1980, 22, 1967.

29 I. Zegkinoglou, P. L. Cook, P. S. Johnson, W. L. Yang, J. H. Guo, D. Pickup, R. Gonzalez-Moreno, C. Rogero, R. E. Ruther, M. L. Rigsby, J. E. Ortega, R. J. Hamers and F. J. Himpsel, J. Phys. Chem. C, 2012, 116, 13877.

30 M. P. Dare-Edwards, J. B. Goodenough, A. Hamnett, K. R. Seddon and R. D. Wright, Discuss. Faraday Soc., 1980, 70, 285.

31 L. Kavan, Chem. Rec., 2012, 12, 131.

32 A. Fujishima, Y. Einaga, T. N. Rao and D. A. Tryk, Diamond Electrochemistry, ed. A. Fujishima, Y. Einaga, T. N. Rao and D. A. Tryk, Elsevier, Amsterdam, 2005, pp. 556-574.

33 (a) A. J. Bard and L. R. Faulkner, Electrochemical Methods: Fundamentals and Applications, John Wiley \& Sons Inc., New York, 2001; (b) S. Trasatti, Pure Appl. Chem., 1986, 58, 955.

34 S. Ermer, S. M. Lovejoy, P. V. Bedworth, D. S. Leung, H. B. Warren, J. A. Epstein, D. G. Girton, L. S. Dries, R. E. Taylor, R. R. Barto, W. Eades, T. E. Van Eck, A. S. Moss and W. W. Anderson, Adv. Funct. Mater., 2002, $12,605$.

35 W. Gajewski, P. Achatz, O. A. Williams, K. Haenen, E. Bustarret, M. Stutzmann and J. A. Garrido, Phys. Rev. B: Condens. Matter Mater. Phys., 2009, 79, 045206.

36 P. E. Laibinis, C. D. Bain and G. M. Whitesides, J. Phys. Chem., 1991, 95, 7017. 